\title{
The Development and Strategy of Chinese Cultural and Creative Design
}

\author{
Wei $\mathrm{Bi}^{1}$ \\ ${ }^{1}$ Tung-Fang Design Institute, Kaohsiung, Taiwan, 000800
}

KEYWORDS: Chinese Cultural and Creative Design; Development Strategy

\begin{abstract}
The development of cultural and creative industries has maintained a good momentum and an important role in the socio-economic system. It is becoming increasingly prominent. Based on the particularity of cultural and creative industries, we believe that it is necessary to learn from the advanced experience of foreign countries on the basis of innovation and development, the development path with Chinese characteristics of cultural and creative industries. In this paper, the design development of cultural and creative industries at home and abroad to sort out study on the sustainable development of design theory, hoping to explore the future development of China's sustainable cultural and creative industries, which have great significance for the promotion of cultural and creative industries to achieve sustainable development. Therefore, based on the study of sustainable development of cultural and creative industries design, design strategy and practice is the focus of this study.
\end{abstract}

\section{Introduction}

In recent years, the Chinese government also attaches great importance to the development of cultural and creative industries. Chinese government early in the Fifth Plenary Session of the Sixteenth pointed out that innovation is a powerful driving force of technological development, China must promote the development of cultural and creative industries, and make it a strategic industry development in many provinces. CPC eighteen report made it clear that in 2020 the cultural industry has become a pillar industry. Cultural and creative industries major cities in China, Taiwan, Hong Kong, as if springing up, various inland cities have started the development of cultural and creative industries. Richard Florida "Creative Class" is mentioned: "Creative industry practitioners gathered at the creative center." In the public space of this freedom, the creative industries who will follow their own industry characteristics, for inspiration, conduct creative industry; creative industries are generally smaller, themed, which makes gathering space for the entire creative industry development, so as to form a creative industry park mode.

\section{Situation of Cultural and Creative Industries}

In 2011, the cultural sector and institutions performing arts groups self-financing rate, the most value for the Shanghai Gao (49.24\%) and lowest in Tibet (2.16\%), a difference of 22.8 times. For several cultural market operators, value most Gao Shandong Province (17 273), the lowest in Qinghai Province (1343), a difference of 12.86 times. Total profit for the cultural market operators, Value most Gao Guangdong Province (15,251,539 thousand), a minimum of Tibet (108,401 thousand), a difference of 140.7 times. For the number of cultural relics, the highest values of Beijing (3720324), a minimum of Chongqing (1551), a difference of 2398.66 times. Total attendance for museums is the highest value in Jiangsu Province (52.12 million people), a minimum of Tibet (21 million people), a difference of 248.19 times. Comparison, the central region of the 
development of the best indicators of the average highest ranking, cultural and creative industries in the western region lagged behind other regions, the index values are low.

Removing the former municipalities of Beijing, Shanghai, Tianjin, ranks among the number of cultural relics, museums total attendance was ranked outside the countdown (This occurs because of the higher level of economic development of the municipality, rich and varied cultural consumption patterns, consumers face more choices). Number of cultural relics and museums to visit various regions of the total number of ranking there is some positive correlation. This is not only with the regional cultural heritage related to the inherent, but also reflects the cultural products consumption, supply to some extent also determine the needs of a certain level. In addition, from a total profit of the regional cultural market operators rankings, ranking behind many cultural relics collection number of areas operating in good condition, indicating that consumption of these products, strong local culture, but insufficient supply, indicating a mismatch between supply and demand of cultural products of each region, therefore, REGION approach should be taken to local conditions, make full use of their own culture, to create a local characteristics of creative culture.

\section{Cultural and Creative Industry Development Strategy Analysis}

Cultural and creative enterprises based on advanced science and technology as a means to provide differentiated, creative-oriented, for-profit organization of cultural goods or services to customers. Cultural and creative industries in the development process, companies bear the culture of innovation of science and technology, the production of cultural and creative products to meet market needs and to create and enhance the values and spirit of the realm of important responsibilities. Therefore, clearly the dominant position of cultural and creative enterprises, and promote the cultural and creative industries state-owned large enterprises, small and medium enterprises and private enterprises healthy, harmonious and sustainable development of practical significance.

Cultural and creative enterprises clearly dominant position in the cultural and technological innovation system is clear in the process of cultural and technological innovation, enterprises, research institutes and universities of the responsibilities and obligations. For a long time, the body of cultural and technological innovation system is not clear. Research institutions responsible for $\mathrm{R}$ $\& \mathrm{D}$, is not responsible for the application and diffusion of technology; responsible for the technical colleges of education and training, R \& D design less, the lack of technology and marketing platform; and business is only responsible for the production and application of technology, the technology less research and development, resulting in a reliance on administrative means to coordinate all production and research of touch, and do not dialogue and other issues. According to relevant statistics, China's local cultural and technological innovation in enterprises, less than ten thousandths of enterprises establish their own R \& D institutions, while in the western countries this ratio is more than $60 \%$. Thus, on the one hand to encourage enterprises to establish research and development institutions, increase cultural and technological innovation investment; on the other hand to urge enterprises and research institutes, Gao and other institutions to the project as a link for strong cooperation, and strive to build a one-stop research new modern cultural and technological innovation system.

In order to give full play to the important role of state-owned large-scale cultural and creative enterprises: First, to establish a modern enterprise system, accelerate the commercial cultural units into enterprises, cultivate qualified market players. For our journalism, publishing, art troupes, radio and television enterprises, should be in accordance with the requirements of modern enterprise system, accelerate the joint-stock reform, improve the corporate governance structure of 
state-owned cultural enterprises become clear property rights, clear responsibilities, separating the management of market players; while promoting the state-owned large-scale cultural and creative enterprises to actively participate in market competition at home and abroad, to bring reform and innovation, management and marketing, enterprise and the market closely together, give full play to the hard power of state-owned cultural capital, influence and driving force ; the second is to speed up the state-owned large-scale cultural and creative enterprises take the group path of development, through the provision of cultural and creative industries Gao degree of concentration, lower transaction costs, obtain economies of scale, achieve economies of scope, thus increasing the economic strength and market competitiveness; while striving to achieve cultural creative enterprises transnational business. For strength, the brand's cultural and creative enterprises, must rely on the means of brand communication, business operations, restructuring and other resources, expand domestic and foreign markets space, to further enhance the competitiveness of the cultural and creative industries, shaping national culture brand, and expand Chinese culture international influence and enhance China's soft power, accelerating culture "going out" pace; third is to accelerate the pace of cultural enterprises listed.

SMEs are an important force in the development of cultural and creative industries. Sound and rapid development of SMEs, it helps improve the socialist market economic system, to stimulate social innovation and vitality. From the process of foreign cultural and creative industries development, the SMEs countries, especially some innovative small businesses tend to have a high level of science and technology, plays a role of the main force. Small and medium scale was not much, but with self-developed patented technology, created by the cultural and creative products with strong international competitiveness. In China, to further the development of cultural and creative industries must be to foster small and medium innovative enterprises for development. For small and medium innovative enterprises to become the main force of the future development of China's cultural and creative industries, should improve the quality and efficiency as a key to further stimulate SME innovation vitality. Policy and institutional support and promote small and medium enterprises to take the road of innovation and development, creating jobs to increase their role in improving people's livelihood important; the structural adjustment, and continuously optimize its product mix, distribution structure scale structure, industrial structure and regions, so that small and medium comprehensive, coordinated and sustainable development; on the level of development, support for small and medium enterprises to take the "specialist special new" road, the development of specialized industrial clusters, Gao continuously improve the internal management level, improve the corporate governance structure, and promote management innovation, system innovation, technology and product innovation to further enhance the overall quality of the enterprise; rich and the establishment of various associations and intermediary organizations, nurture the body, build a platform, enhanced functions, improve the mechanism, improve the quality of Gao, small and medium enterprises to build three-dimensional open coordinated development service system.

Learn from the successful experience of foreign cultural and creative industries can be found, the successful development of cultural and creative enterprises, the public sector must change a single model to achieve a variety of forms of ownership and common development. According to statistics, currently the private economy to create cultural industry has accounted for more than $50 \%$ of total value added of the cultural industry, employment accounted for $67 \%$ of total employment, a number of private cultural and creative enterprises, such as Huayi Brothers, day boat culture, Galloping Horse, Huace, Wanda cinemas and other private enterprises Pat start bigger and stronger, and successfully entered the capital markets. Private enterprises play an increasingly important role in 
the cultural and creative industries. Private enterprises flexible mechanism has high market sensitivity. Private Entrepreneurs' Innovation and strong, rich experience of life and society more profound understanding of the market has a keen reaction, can quickly grasp the pulse of the market time to adjust production and management direction; a high level of creativity of artists, creative thinking is flexible, fashion has a unique grasp of consumer trends is very sensitive to the creative direction will be adjusted on the basis of inspiration, which is more market flexibility. Private enterprises are extremely innovative. Private enterprises less susceptible to stripe box limits on the creative force of individual talent, skill and wisdom, with a strong burst of power to stimulate action; private enterprise and civil cultural force has a natural affinity and bonding force for the development of national technology industry has a natural Advantage. Statistics show that in 2009, nationwide R \& D activities of the above-scale enterprises, a total of 23,953 small enterprises, accounting for above-scale enterprises 65.8 percent, of which private enterprises reached 16,153, accounting for $67.4 \%$ of small businesses.

\section{Conclusion}

It is a collection of cultural and creative industries economy and culture, but also the inevitable path of development of urban renewal. Based on cultural and creative industries on the basis of old industrial buildings of the city can not only promote economic growth, enhance the competitiveness of the city, you can also reshape the image of the city from the psychological point of view of regional culture. Therefore, at this stage, highly developed knowledge-based economy of today, the development of cultural and creative industrial park has an important impact on the city. In this context, the paper design of sustainable cultural and creative industries studied, especially for analysis for transformational cultural and creative industries on the old industrial architectural heritage, from the current development of cultural and creative industries at home and abroad, to find a place worth learning ; from the cultural and creative industries function, it analyzes its principles of sustainable design, comprehensive evaluation system, in order to construct theoretical system of cultural and creative industries; in terms of architecture, color, environment, landscape, lighting effects, and other public spaces can analyze cultural and creative industries continuous design content; cultural and creative industries and building space utilization, ecological design, art design concepts and other think. Finally, the typical case - designing sustainable cultural and creative industries Taiyuan Wayao analysis, design principles of sustainable cultural and creative industry park, methods, content inspection, thereby reflecting the rationality of research results.

\section{References}

[1] Bell, D. The Cultural Contradictions of Capitalism (20th ed.) [M]. New York:. Basic Books, 1976.

[2] Bilton, C. Management and Creativity: From Creative Industries to Creative Management [M]. Wiley-Blackwell, 2006.

[3] Caves, R. Creative Industries: Contracts between Art and Commerce [M]. Massachusetts:. Harvard University Press, 2002.

[4] Cowen, T In Praise of Commercial Culture [M]. Cambridge, MA:. Harvard University Press, 1998.

[5] Davies R. \& Sigthorsson G. Introducing the Creative Industries: From Theory to Practice [M]. London:. Sage, 2013. 